\title{
A Four-Diode Full-Wave Ionic Current Rectifier Based on Bipolar Membranes: Overcoming the Limit of Electrode Capacity
}

Erik O. Gabrielsson, Per Janson, Klas Tybrandt, Daniel T. Simon and Magnus Berggren

\author{
Linköping University Post Print
}

\section{Tweet}

N.B.: When citing this work, cite the original article.

Original Publication:

Erik O. Gabrielsson, Per Janson, Klas Tybrandt, Daniel T. Simon and Magnus Berggren, A Four-Diode Full-Wave Ionic Current Rectifier Based on Bipolar Membranes: Overcoming the Limit of Electrode Capacity, 2014, Advanced Materials, (26), 30, 5143-5147.

http://dx.doi.org/10.1002/adma.201401258

Copyright: Wiley-VCH Verlag http://www.wiley-vch.de/publish/en/

Postprint available at: Linköping University Electronic Press

http://urn.kb.se/resolve?urn=urn:nbn:se:liu:diva-110403 


\section{WILEY-VCH}

DOI: $10.1002 /(($ please add manuscript number $))$

Article type: Communication

\section{A Four-Diode Full-Wave Ionic Current Rectifier Based on Bipolar Membranes: Overcoming the Limit of Electrode Capacity}

Erik O. Gabrielsson, Per Janson, Klas Tybrandt, Daniel T. Simon and Magnus Berggren*

E. O. Gabrielsson, P. Janson, Dr. K. Tybrandt, Dr. D. T. Simon, Prof. M. Berggren

Laboratory of Organic Electronics, Linköping University, SE-601 74 Norrköping, Sweden E-mail: magnus.berggren@liu.se

Keywords: bioelectronics, ionics, ion transport, bipolar membranes, conjugated polymer electrodes

Electrokinetic transport is found in several life science related technologies, such as electroosmotic pumps, ${ }^{[1]}$ gel electrophoresis, ${ }^{[2]}$ and drug delivery systems. ${ }^{[3]}$ The driving force in these systems is an ionic DC, which typically is generated by continuous electrolysis at metal electrodes. ${ }^{[4-6]}$ However, such reactions are not ideal, as they often generate $\mathrm{pH}$ fluctuations, gases, or other undesired chemical products. ${ }^{[4,7]}$ Aside from disruption of chemical equilibria, ${ }^{[8]}$ such side-products can also have mechanical disadvantages. For example, when utilized in microfluidic systems, special care must be taken to avoid blocking of channels by gas bubbles. ${ }^{[5]}$ Further, in bioelectronic applications, potentially harmful chemical species generated from electrolysis can have significant detrimental effects on the fragile biochemical microenvironment. ${ }^{[9]}$ For these systems, the electrodes must be operated in the polarizable regime, i.e. charging and discharging of electric double layers without electrolysis. However, only a small amount of charge can be passed through a conventional metal electrode in the polarizing regime. To improve the electrode capacity, the effective electrode area can be increased, e.g. by using conducting polymer electrodes. ${ }^{[10]}$ Conducting polymers have been explored in several organic bioelectronic devices, such as polymer drug delivery electrodes ${ }^{[11]}$ and organic electronic ion pumps (OEIPs). ${ }^{[12]}$ Although conducting polymers improve the electrode capacity significantly, ${ }^{[10]}$ their finite capacity still prohibits 


\section{WILEY-VCH}

extended undisrupted drug delivery in vivo, i.e., they cannot sustain extended ionic DC fluxes before depletion of redox centers in the electrodes.

Reversible redox switching has previously been demonstrated for conducting polymers in electrochromic displays ${ }^{[13]}$ and super capacitors. ${ }^{[14]}$ Conducting polymer electrodes can thus maintain an ionic AC of high frequency without compromising their capacity and performance. It is therefore tempting to derive an electrochemical concept that converts an ionic $\mathrm{AC}$, generated from oscillating polarizable electrodes, into an ionic $\mathrm{DC}$, in order to circumvent the limitations imposed by electrode capacity. In conventional electronics conversion from AC to DC is often achieved by full-wave rectification. A typical full-wave rectifier circuit comprises a four-diode bridge, in which the diodes are arranged in such a way that upon application of an input voltage, one pair of diodes is forward biased (conductive state) while the second pair is reverse biased (non-conductive). When the input polarity changes, i.e. when applying an AC input, the bias states of the diodes are reversed. However, the diodes are configured in such a way that the output current always goes in the same direction, i.e. the input signal is rectified.

Here, we combine ion conducting diodes, the well-know four-diode bridge rectifier circuit and conducting polymer electrodes to construct a component that is capable to convert an ionic AC signal into a DC flux of ions. Using this approach, the included conducting polymer electrodes can be repeatedly reduced and oxidized, within their polarizable regime by an AC input thus avoiding electrode side-reactions, while still generating an ionic DC current in the circuit. Our integrated ionic circuit is fabricated using conventional microfabrication techniques on a flexible plastic substrate. This allows for easy integration with other ionic devices, made using identical or similar fabrication techniques, here demonstrated by the incorporation of a simple electrophoretic drug delivery device.

To implement a diode bridge for rectification of ionic currents one must utilize iontronics, a new class of devices and circuits which employs ions, rather than electrons, as charge 


\section{WILEY-VCH}

carriers. ${ }^{[15,16]}$ Several types of ion diodes have been reported, exemplified by electrolytic, ${ }^{[17]}$ nanofluidic, ${ }^{[18]}$ and bipolar membrane ${ }^{[19-21]}(\mathrm{BM})$ diodes. Among these, the latter are best suited for use at physiological conditions (i.e., high salt concentration and near neutral $\mathrm{pH}$ ), as nanofluidic and electrolytic diodes typically require $<0.1 \mathrm{M}$ electrolyte concentration ${ }^{[22]}$ and acidic/alkali electrolytes ${ }^{[17]}$ for proper operation, respectively. A BM is constructed from the combination of highly charged anion- and cation-selective membranes, ${ }^{[23]}$ and can therefore retain ion selectivity even at physiological conditions. For this reason, they are particularly suited for bioelectronic applications. BMs are ion current rectifiers, as ions accumulate in the $\mathrm{BM}$ at forward bias (leading to high ionic conductivity) and are depleted from the BM interface at reverse bias (low ionic conductivity ${ }^{[24]}$ (Figure 1a). Highly-rectifying and swiftly operating BM-based diodes were constructed by layering photolithographically patterned poly(styrenesulfonate) (PSS, cation-selective) with the a quaternary polyphoshonium ${ }^{[21]}\left(\mathrm{PVBPPh}_{3}\right.$, anion-selective) (Figure $\left.1 \mathrm{~b}\right)$ on a plastic substrate, using SU-8 as insulator (Figure 1c). Electronically conductive poly(3,4ethylenedioxythiophene):poly(styrenesulfonate) (PEDOT:PSS) electrodes, covered by aqueous electrolyte, were used for electron-to-ion conversion (and vice versa) in the circuit, following the redox reaction PEDOT $^{+}: \mathrm{PSS}^{-}+\mathrm{M}^{+}+\mathrm{e}^{-} \leftrightarrow$ PEDOT $^{0}+\mathrm{M}^{+}: \mathrm{PSS}^{-}$, in which ions are exchanged between the electrode and the electrolyte. The resulting diodes exhibited good performance, with rectification ratio (the ratio between forward and reverse bias currents), close to 300 at $\pm 4 \mathrm{~V}$ (Figure 1d) and a $10 \mathrm{~s}$ on/off switch time (Figure 1e).

As a first demonstration of the possibility of ionic full-wave rectification, we constructed the typical diode bridge circuit with four BM diodes (Figure 2a). PEDOT:PSS electrodes were patterned at each input and output terminal, in order to accommodate the electron-to-ion conversion between the external electrical circuit and the ionic current in the bridge circuit. As an input voltage $\left(V_{\text {in }}\right)$ is applied, ionic current flows through the bridge either according to 


\section{WILEY-VCH}

Figure $2 b$ or $2 c$, depending on the polarity of the input. The resulting rectified ionic current can be determined by measuring the electronic current between the output electrodes. To test the rectifying property of the ionic four-diode bridge, a square wave voltage of $\pm 4 \mathrm{~V}$ with $600 \mathrm{~s}$ period was applied at $V_{\text {in }}$, and the input $\left(I_{\text {in }}\right)$ and output $\left(I_{\text {out }}\right)$ current was monitored (Figure 2d). As expected from a four-diode bridge rectifier, $I_{\text {out }}$ was monopolar regardless of the polarity of $I_{\text {in }}$, except for short transient spikes when $V_{\text {in }}$ changed polarity. Further, due to the high rectification ratio of the individual BM-diodes, the magnitude of $I_{\text {out }}$ and $I_{\text {in }}$ closely matched at steady state. Thus, it is possible to use BM ion diodes to efficiently full-wave rectify ionic currents. The efficiency, calculated as the integrated $I_{\text {out }}$ divided by the integrated absolute $I_{\text {in }}$, reached $86 \%$. The main loss of efficiency occurred during the switch of $V_{\text {in }}$ polarity, while the efficiency at steady state was close to $95 \%$. For higher input frequency, less time is spent at steady state and the efficiency decreased to $73 \%$ and $79 \%$ when using $120 \mathrm{~s}$ and $240 \mathrm{~s}$ periods, respectively. Thus, the efficiency could be further increased by using alternating input signals of even lower frequency.

In the bridge circuit in Figure 2, the DC output is configured as an electric connection between the two output PEDOT:PSS electrodes. The DC output of the bridge can also be configured for ionic flux, where a cation-selective PSS channel connects the two output reservoirs (Figure 3a-b). This connection mimics the previously reported OEIP drug delivery device. ${ }^{[12]}$ The OEIP has been utilized for electrophoretic transport and delivery of charged biomolecules at high spatiotemporal resolution for regulation of physiology and functions in both in vitro ${ }^{[12]}$ and in vivo ${ }^{[25]}$ systems. Normally, the OEIP is composed of an ion-selective channel located between a source (S) and a target $(\mathrm{T})$ electrolyte, each connected to PEDOT:PSS electrodes used for ionic DC generation. In the present study, the electrodes are replaced by the four-diode bridge circuit, in which an AC input signal $\left(V_{\text {in }}\right)$ is rectified into an ionic DC through the cation-selective channel between the $\mathrm{S}$ and $\mathrm{T}$ electrolytes (Figure $3 \mathrm{c}$ and 3d). Thus, cations are transported from the positive biased S electrolyte to the negative biased 


\section{WILEY-VCH}

T electrolyte for both positive and negative $V_{\text {in }}$. Electrodes placed in the output electrolytes can be used to record the voltage between $\mathrm{S}$ and $\mathrm{T}\left(V_{\text {out }}\right)$. This DC voltage, created from the rectified AC input signal, is the driving voltage of the cation transport through the cationselective channel.

The cation-selective channel inside the ionic four-diode bridge was used for electrophoretic delivery of acetylcholine (ACh) from $\mathrm{S}$ to $\mathrm{T}$ using an $\mathrm{AC}$ input signal (Figure $3 \mathrm{e}$ ). ACh is a neurotransmitter which acts on both the peripheral and central nervous systems, is relevant for several of the signalling cascades in humans, and has been implicated in some neurodegenerative diseases. The bridge circuit was addressed with a $\pm 8 \mathrm{~V}$ square wave $V_{\text {in }}$ signal at $1200 \mathrm{~s}$ period, and $I_{\text {in }}$ and $V_{\text {out }}$ were electrically measured. At each switch of $V_{\text {in }}$, the whole T electrolyte (volume $5 \mu \mathrm{l}$ ) was sampled and replaced with fresh electrolyte, and the ACh concentration in the samples was later measured using a fluorometric enzyme kit. The ionic four-diode bridge with the cation-selective output channel shows a $V_{\text {out }}$ of $\sim 6.8 \mathrm{~V}$ at steady-state. In similarity to the $I_{\text {out }}$ in Figure $2 \mathrm{~d}$, the $V_{\text {out }}$ remains positive, i.e. rectification of $V_{\text {in }}$ occurs, except for short negative spikes when the $V_{\text {in }}$ switches polarity. The stable $V_{\text {out }}$ across the cation-selective channel suggests that a continuous ion current is obtained through the channel. This was confirmed by measuring the amount of ACh delivered to the T electrolyte. During each half-period of the $V_{\text {in }}$ square signal around $120 \mu \mathrm{C}$, or $1.2 \mathrm{nmol}$, of electronic charge alternatingly reduces and oxidizes the input electrodes, thus driving the circuit. In the T electrolyte, a continuous delivery of ACh is detected, with a mean transport of $1.1 \mathrm{nmol}$ per half-period. Over the total run of the experiment, $11.4 \mathrm{nmol} \mathrm{ACh}$, equalling 1.1 $\mathrm{mC}$, was delivered using only $120 \mu \mathrm{C}$ electrode capacity (within the PEDOT:PSS electrodes polarization regime, see Figure S1). The efficiency over the 5 periods, calculated as measured ACh divided by the integrated absolute $I_{\text {in }}$, reaches $83 \%$. Thus, the ionic four-diode bridge enables nearly-undisturbed delivery of ions over an extended period of time without the concern of limited electrode capacity or electrode side-reactions. Also, the incorporation of an 


\section{WILEY-VCH}

ionic output circuit only marginally reduced the efficiency of the bridge circuit, and the added loss off efficiency can mainly be attributed to less than ideal selectivity of the cation-selective channel. Due to the long distance between the channel outlet and the BM diodes $(1 \mathrm{~mm})$ and a relatively much higher concentration of $\mathrm{Na}^{+}(0.1 \mathrm{M})$ as compared to $\mathrm{ACh}$ (maximum $\sim 0.22$ $\mathrm{mM}$ ) in $\mathrm{T}$, transport of delivered $\mathrm{ACh}$ from $\mathrm{T}$ is negligible.

In conclusion, the use of BM ion diodes enables the construction of an ionic four-diode bridge circuit, which can be used for full-wave rectification of ionic currents. The rectification of input square wave signals was confirmed by measuring output of both electric and ionic currents. Compared to previously reported mechanical valve based ionic rectifying bridges ${ }^{[26,27]}$ our diode-based bridge has no moving parts and is relatively much simpler, offers a greater possibility of miniaturization, and is thus more suited for implantable devices. Bridges based on rectifying transmembrane proteins have also been reported ${ }^{[28]}$. Although very interesting from a scientific point of view these bridges have limited operational voltage window $^{[29]}$. However, compared to mechanical valves ${ }^{[26]}$ and protein based bridges ${ }^{[28]}$, which have shown to operate at 1 and $0.1 \mathrm{~Hz}$, respectively, the device reported here suffers from low efficiency at high frequencies. This is due to a long switching time of our present large-sized $\mathrm{BM}$ diodes. The speed and therefore the high frequency efficiency can be improved by minimizing the size of the BM interfaces ${ }^{[21]}$. Further, as the presented device is fabricated using high-resolution photolithography techniques, reducing the dimensions of the bridge circuit down to $1 \mathrm{~mm}^{2}$ is well within reach. The delivery of the neurotransmitter ACh through a cation-selective channel (Figure 3 ) represents a simple example of the capability and promise of the ionic four-diode bridge. While the reported ACh delivery time-scale is magnitudes longer than found in synaptic signalling, ACh also exhibits slower dynamics as a neuromodulator in the brain ${ }^{[30]}$, for which the presented system might be more relevant. The function of the ionic four-diode bridge can be further extended by exchanging the cationselective channel with any ionic circuit that requires constant driving current for extended 


\section{WILEY-VCH}

durations, such as devices for electrokinetic driven transport. The bridge could, for example, be integrated into ionic drug delivery devices for in vivo applications, ${ }^{[25]}$ to minimize the electrode size and to extend the device lifetime. Further, the bridge could drive ionic circuits incorporating advanced logic functions comprising ion transistors ${ }^{[31]}$ and diodes. ${ }^{[19,20]}$ In such applications, the device area is largely consumed by the electrodes and the ionic four-diode bridge could help to minimize the required electrode area. Moreover, with an ionic rectifier at hand, the performance of various conducting polymer electrochemical devices can be improved. We therefore see the ionic four-diode bridge as a useful iontronic circuit element in the development of future ionic bioelectronics, charge storage, sensor and interface devices.

\section{Experimental Section}

Preparation of $\mathrm{PVBPPh}_{3}$ : The same procedure as previously reported ${ }^{[21]}$ was used for obtaining the quaternized polyphosphonium. Briefly, $5 \mathrm{ml}$ of a $200 \mathrm{mg} / \mathrm{ml}$ solution of poly(vinylbenzyl chloride) (PVBC, avg. MW 100000, Sigma-Aldrich) in tetrahydrofuran, filtered through a $0.2 \mu \mathrm{m}$ polytetrafluoroethylene membrane, was mixed with $1720 \mathrm{mg}$ of triphenylphospine (Sigma-Aldrich). The mixture was heated in a water bath for $24 \mathrm{~h}$ at $60{ }^{\circ} \mathrm{C}$, after which excess solvent was removed and the product dried in vacuum. After addition of $4.5 \mathrm{ml} \mathrm{H}_{2} \mathrm{O}$ and $2.46 \mathrm{ml}$ 1-propanol, the mixture was filtered through a $0.2 \mu \mathrm{m}$ nylon membrane, and additional $6 \mathrm{ml}$ of $\mathrm{H}_{2} \mathrm{O}$ and $8 \mathrm{ml}$ of 1-propanol was added.

Manufacturing of devices: The general procedure for manufacturing ion diodes with $\mathrm{PVBPPh}_{3}$ has been reported before ${ }^{[21]}$ and was followed without any modifications. Briefly, PEDOT:PSS on polyethylene terephthalate substrates (AGFA-Gevaert Orgacon ${ }^{\mathrm{TM}} \mathrm{F}-350$ ) was patterned by standard photolithography using a Karl Suss MA/BM 6 mask aligner and a $\mathrm{CF}_{4} / \mathrm{O}_{2}$ plasma etch to define electrodes and cation-selective channels. The cation-selective channels were selectively overoxidized using aqueous sodium hypochlorite solution (1 vol\%) for $45 \mathrm{~s}$, in order to render the PEDOT electronically non-conductive while retaining the ionic conductivity of $\mathrm{PSS}^{[32]}$. A $2.5 \mu \mathrm{m}$ thick SU8-layer (SU8-2002, MicroChem) was patterned on 


\section{WILEY-VCH}

top. The anion-selective membrane $\left(\mathrm{PVBPPh}_{3}\right)$ was deposited by spin coating, patterned using photolithography and a $\mathrm{CF}_{4} / \mathrm{O}_{2}$ plasma, and sealed with a $10 \mu \mathrm{m}$ thick SU8-layer (SU8-2010, MicroChem). Silver contacts and $\mathrm{Ag} / \mathrm{AgCl}$ were painted on the electrodes.

Characterization of devices: Devices were soaked in $\mathrm{H}_{2} \mathrm{O}$ for at least $24 \mathrm{~h}$ before measurements. A Keithley 2602A source meter, programmed via LabVIEW, was used for sourcing and measuring voltages and currents with a $4 \mathrm{~Hz}$ sampling frequency.

ACh measurements: A fluorometric ACh assay kit (Amplex ${ }^{\circledR}$ Red acetylcholine/acetylcholinesterase assay kit, Molecular Probes) was used to measure the ACh concentration in the collected samples. The assay was performed with excitation at $550 \mathrm{~nm}$ and emission at $590 \mathrm{~nm}$ using a Tecan Safire 2 plate reader after 60 minutes incubation.

\section{Supporting Information}

Supporting Information is available from the Wiley Online Library or from the author.

\section{Acknowledgements}

This research was financed by VINNOVA 2010-00507 (OBOE Miljö), the EU Seventh Framework Programme (FP7/2007-2013) under grant agreement 280772 project iONE-FP7, the Swedish Research Council (621-2011-3517), the Swedish foundation for strategic research (RMA-11:0104), the EU Seventh Framework Programme Marie Curie (PITN-GA2013-607896) project OrgBIO, the Advanced Functional Materials Center at Linköping University, and the Önnesjö foundation. We also thank Rozalyn Simon at Linköping University for experimental support regarding the acetylcholine assay.

Received: ((will be filled in by the editorial staff))

Revised: ((will be filled in by the editorial staff)) Published online: ((will be filled in by the editorial staff))

[1] Chuan-Hua Chen, J. G. Santiago, J. Microelectromech. Syst. 2002, 11, 672.

[2] R. Hagedorn, T. Schnelle, T. Müller, I. Scholz, K. Lange, M. Reh, Electrophoresis 2005, 26, 2495.

[3] P. E. Boukany, A. Morss, W.-C. Liao, B. Henslee, H. Jung, X. Zhang, B. Yu, X. Wang, Y. Wu, L. Li, K. Gao, X. Hu, X. Zhao, O. Hemminger, W. Lu, G. P. Lafyatis, L. J. Lee, Nature Nanotech 2011, 6, 747.

[4] A. Persat, M. E. Suss, J. G. Santiago, Lab Chip 2009, 9, 2454.

[5] D. Kohlheyer, J. C. T. Eijkel, A. van den Berg, R. B. M. Schasfoort, Electrophoresis 2008, 29, 977.

[6] J. Voldman, Annual Review of Biomedical Engineering 2006, 8, 425. 


\section{WILEY-VCH}

[7] T. Revermann, S. Götz, J. Künnemeyer, U. Karst, Analyst 2008, 133, 167.

[8] A. R. Minerick, A. E. Ostafin, H.-C. Chang, Electrophoresis 2002, 23, 2165.

[9] A. Oki, Y. Takamura, Y. Ito, Y. Horiike, Electrophoresis 2002, 23, 2860.

[10] P. G. Erlandsson, N. D. Robinson, Electrophoresis 2011, 32, 784.

[11] M. R. Abidian, D. H. Kim, D. C. Martin, Adv Mater 2006, 18, 405.

[12] J. Isaksson, P. Kjaell, D. Nilsson, N. D. Robinson, M. Berggren, A. Richter-Dahlfors, Nature Materials 2007, 6, 673.

[13] G. Sonmez, C. K. F. Shen, Y. Rubin, F. Wudl, Angew. Chem. Int. Ed. 2004, 43, 1498.

[14] J. M. D’Arcy, M. F. El-Kady, P. P. Khine, L. Zhang, S. H. Lee, N. R. Davis, D. S. Liu, M. T. Yeung, S. Y. Kim, C. L. Turner, A. T. Lech, P. T. Hammond, R. B. Kaner, Acs Nano 2014, 8, 1500.

[15] G. Tarabella, F. M. Mohammadi, N. Coppede, F. Barbero, S. Iannotta, C. Santato, F. Cicoira, Chem Sci 2013, 4, 1395.

[16] S. Park, T. Chung, H. Kim, Microfluid Nanofluid 2009, 6, 315.

[17] L. Hegedüs, N. Kirschner, M. Wittmann, P. Simon, Z. Noszticzius, T. Amemiya, T. Ohmori, T. Yamaguchi, Chaos 1999, 9, 283.

[18] H. Daiguji, Y. Oka, K. Shirono, Nano Lett 2005, 5, 2274.

[19] J. H. Han, K. B. Kim, H. C. Kim, T. D. Chung, Angew. Chem. Int. Ed. 2009, 48, 3830 .

[20] E. O. Gabrielsson, K. Tybrandt, M. Berggren, Lab Chip 2012, 12, 2507.

[21] E. O. Gabrielsson, M. Berggren, Biomicrofluidics 2013, 7, 064117.

[22] R. Schoch, J. Han, P. Renaud, Rev. Mod. Phys. 2008, 80, 839.

[23] V. J. Frilette, J. Phys. Chem. 1956, 60, 435.

[24] P. Ramirez, H. Rapp, S. Reichle, H. Strathmann, S. Mafé, J. Appl. Phys. 1992, 72, 259.

[25] D. T. Simon, S. Kurup, K. C. Larsson, R. Hori, K. Tybrandt, M. Goiny, E. W. H. Jager, M. Berggren, B. Canlon, A. Richter-Dahlfors, Nat Mater 2009, 8, 742.

[26] G. Y. Fridman, C. C. Della Santina, IEEE Transactions on Neural Systems and Rehabilitation Engineering 2013, 21, 319.

[27] A. Brask, D. Snakenborg, J. P. Kutter, H. Bruus, Lab Chip 2006, 6, 280.

[28] G. Maglia, A. J. Heron, W. L. Hwang, M. A. Holden, E. Mikhailova, Q. Li, S. Cheley, H. Bayley, Nature Nanotech 2009, 4, 437.

[29] S. Punnamaraju, A. J. Steckl, Langmuir 2011, 27, 618.

[30] M. R. Picciotto, M. J. Higley, Y. S. Mineur, Neuron 2012, 76, 116.

[31] K. Tybrandt, R. Forchheimer, M. Berggren, Nat Commun 2012, 3.

[32] P. Tehrani, A. Kanciurzewska, X. Crispin, N. D. Robinson, M. Fahlman, M. Berggren, Solid State Ionics 2007, 177, 3521. 
a
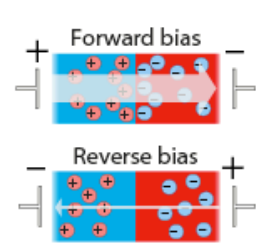

Anode $\gg$ Cathode

Anion selective

+ Mobile cation

- Cation selective - Mobile anion

$c$
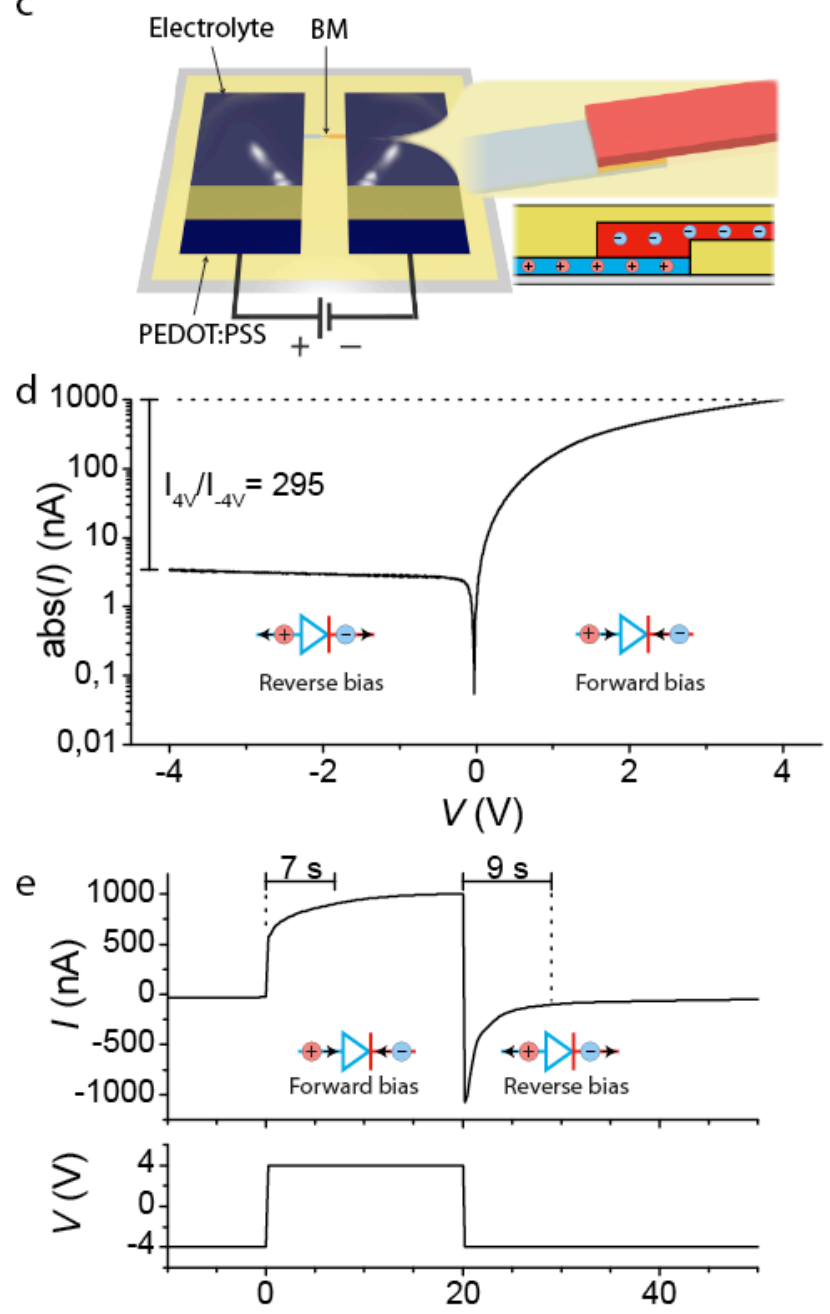

Time (s)

Figure 1. BM diodes. a) Rectification is observed in a BM due to the difference in mobile ion concentration at the BM interface between forward and reverse bias. b) Chemical structures of the cation-selective PSS and the anion-selective $\mathrm{PVBPPh}_{3} . \mathrm{c}$ ) Illustrations of a BM diode, showing the cation- and anion-selective membranes (overlap 50x50 $\mu \mathrm{m}$ ) connected to electrolyte-covered PEDOT:PSS electrodes separated by $1 \mathrm{~mm}$. d) Current-voltage steadystate and E. transient characteristics for a BM diode. 
a
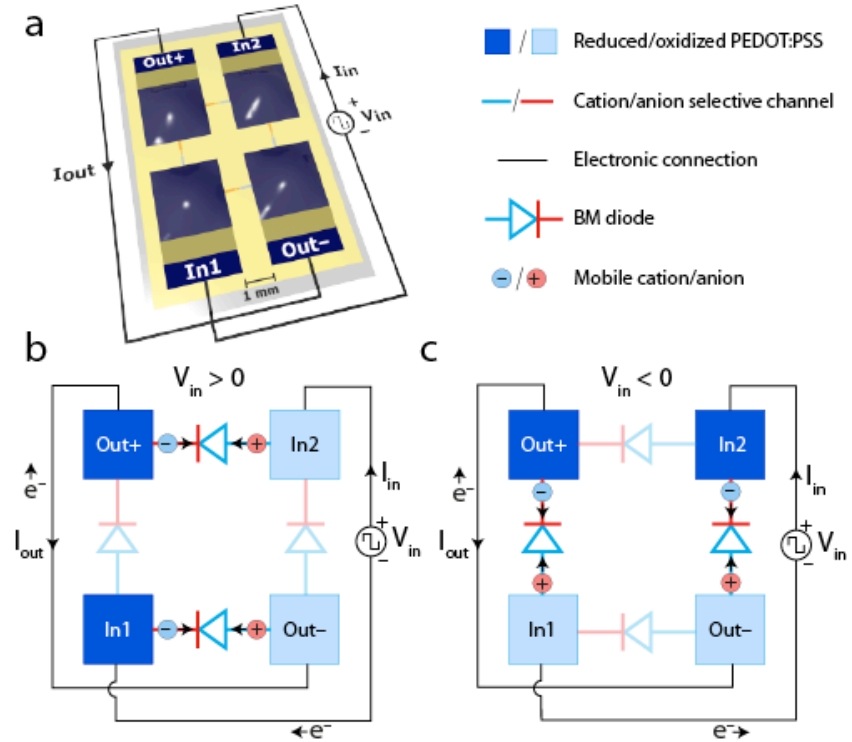

d
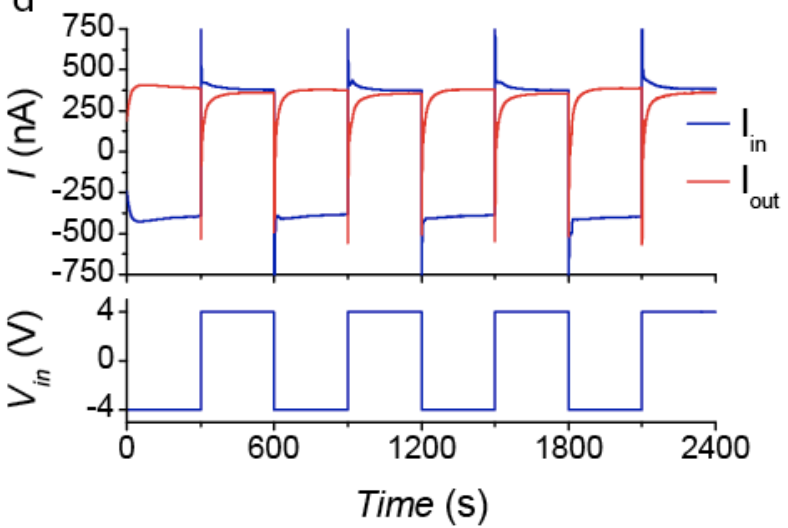

Figure 2. The four-diode full wave ion current rectifier. a) Structure and connections of an ionic four-diode bridge with electronic output connection. b-c) Ionic current pathways depending on $V_{\text {in }}$ polarity. Electrodes being reduced/oxidized are shown in dark/pale blue, reverse biased diodes are indicated by faded colors. d) Electronic AC input and DC output through the bridge. 

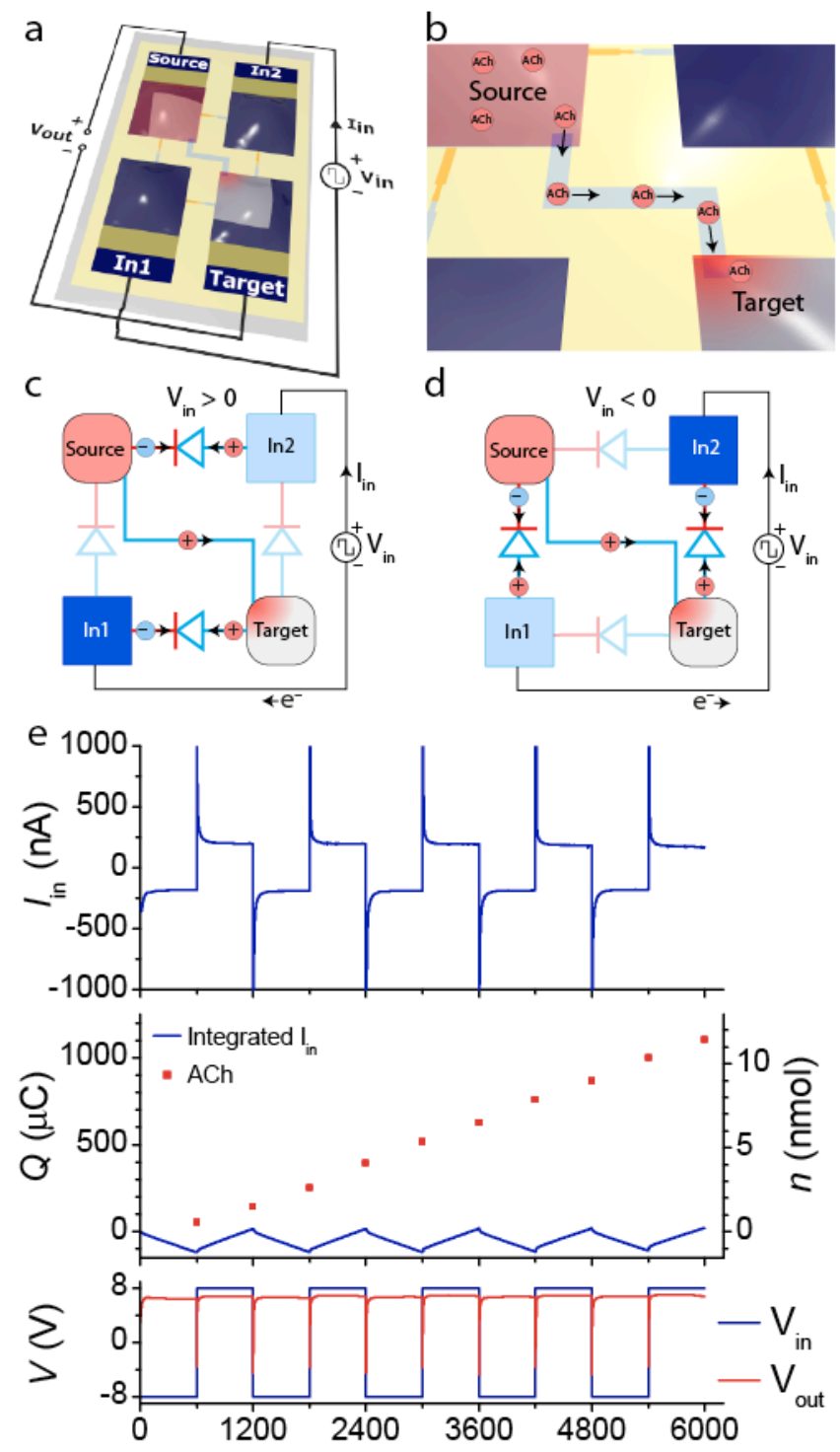

Time (s)

Figure 3. ACh delivery decoupled from the electrode capacity. a-b) Structure and connections of an ionic four-diode bridge with a cation-selective channel as output connection. The channel is $100 \mu \mathrm{m}$ wide and $1.5 \mathrm{~mm}$ long. c-d) Ionic current pathways, biasing of the diodes and cation delivery through the output connection. The colouring matches Figure 2.

e) Switching of the bridge, integrated $I_{\text {in }}$ and measured output delivery of ACh. 


\section{WILEY-VCH}

Full-wave rectification of ionic currents is obtained by constructing the typical four-diode bridge out of ion conducting bipolar membranes. Together with conjugated polymer electrodes addressed with alternating current, the bridge allows for generation of a controlled ionic direct current for extended periods of time without the production of toxic species or gas typically arising from electrode side-reactions.

Keywords: bioelectronics, ionics, ion transport, bipolar membranes, conjugated polymer electrodes

Erik O. Gabrielsson, Per Janson, Klas Tybrandt, Daniel T. Simon and Magnus Berggren*

A Four-Diode Full-Wave Ionic Current Rectifier Based on Bipolar Membranes: Overcoming the Limit of Electrode Capacity

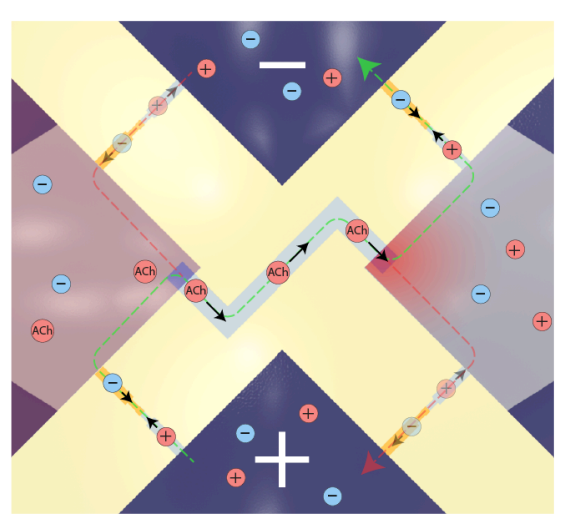




\section{WILEY-VCH}

Copyright WILEY-VCH Verlag GmbH \& Co. KGaA, 69469 Weinheim, Germany, 2013.

\section{Supporting Information}

\section{A Four-Diode Full-Wave Ionic Current Rectifier Based on Bipolar Membranes: Overcoming the Limit of Electrode Capacity}

Erik O. Gabrielsson, Per Janson, Klas Tybrandt, Daniel T. Simon and Magnus Berggren*

E. O. Gabrielsson, P. Janson, Dr. K. Tybrandt, Dr. D. T. Simon, Prof. M. Berggren Laboratory of Organic Electronics, Linköping University, SE-601 74 Norrköping, Sweden E-mail: magnus.berggren@liu.se

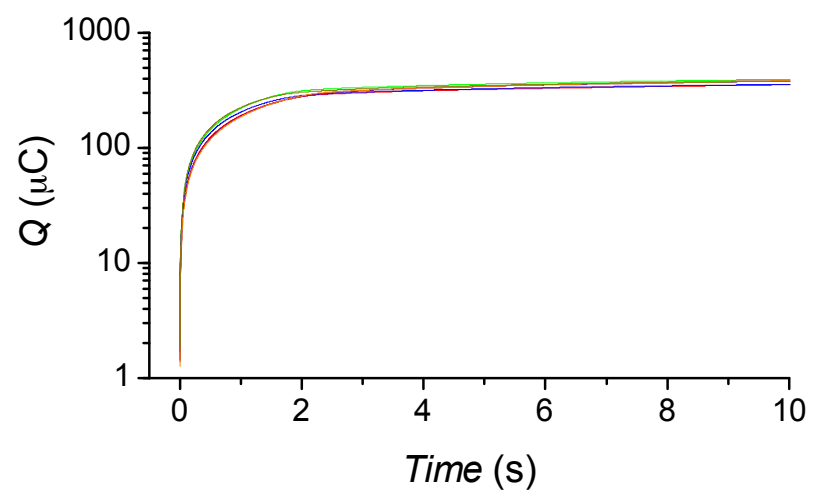

Figure S1. PEDOT:PSS electrode capacity. Oxidation of pristine (partly oxidized)

PEDOT:PSS electrodes $\left(6.25 \mathrm{~cm}^{2}\right.$ area) in $0.1 \mathrm{M} \mathrm{NaCl}$ at $1.5 \mathrm{~V}$ vs an $\mathrm{Ag} / \mathrm{AgCl}$ (in $3 \mathrm{M} \mathrm{NaCl}$ ) reference electrode. After $\sim 200 \mu \mathrm{C}$ the rate decreases, indicating the limit of the PEDOT:PSS electrodes polarization regime. Measurements were performed using a $\mu$ AutolabIII potentiostat (Metrohm Autolab). 